\title{
Directional Selective Nonlinear Transmission of Femtosecond Pulses in Glass-Metal Nanocomposites
}

Mohan, Sabitha; Graener, Heinrich; Bache, Morten; Seifert, Gerhard

Published in:

CLEO/Europe 2013 - European Conference on Lasers and Electro-Optics

Link to article, DOI:

10.1109/cleoe-iqec.2013.6800917

Publication date:

2013

Link back to DTU Orbit

Citation (APA):

Mohan, S., Graener, H., Bache, M., \& Seifert, G. (2013). Directional Selective Nonlinear Transmission of Femtosecond Pulses in Glass-Metal Nanocomposites. In CLEO/Europe 2013 - European Conference on Lasers and Electro-Optics IEEE. https://doi.org/10.1109/cleoe-iqec.2013.6800917

\section{General rights}

Copyright and moral rights for the publications made accessible in the public portal are retained by the authors and/or other copyright owners and it is a condition of accessing publications that users recognise and abide by the legal requirements associated with these rights.

- Users may download and print one copy of any publication from the public portal for the purpose of private study or research.

- You may not further distribute the material or use it for any profit-making activity or commercial gain

- You may freely distribute the URL identifying the publication in the public portal 


\title{
Directional Selective Nonlinear Transmission of Femtosecond Pulses in Glass-Metal Nanocomposites
}

\author{
Sabitha Mohan ${ }^{1,2}$, Heinrich Graener ${ }^{2}$, Morten Bache ${ }^{1}$, Gerhard Seifert ${ }^{3}$ \\ 1. DTU Fotonik, Department of Photonics Engineering, Technical University of Denmark, DK-2800 Kgs. Lyngby, Denmark
2. Physics Institute, Martin-Luther-University Halle-Wittenberg, Institut für Physik, D-06099 Halle, Germany
Present address: University of Hamburg, D-20146 Hamburg, Germany
3. Centre of Innovation Competence SiLi-nano ${ }^{\circledR}$, Martin-Luther-University Halle-Wittenberg, D-06120 Halle, Germany
}

Third-order nonlinear optical materials have gained special attention due to their unique role in all optical switching, optical limiting and optical communication applications. Composite materials based on nanoparticles (NP) in transparent matrix proved to be promising candidates whose $\chi^{(3)}$ can be adequately tailored by tuning the material parameters such as size, shape, and filling factor of nanoparticles [1].

The samples studied are metallic nanocomposites consisting of glass containing spherical silver nanoparticles (Ag NP) arranged in a two-layer geometrical structure. The nanoparticles are distributed within a thin surface layer of glass of thickness few microns, while the remainder of the sample thickness $(1 \mathrm{~mm})$, consists of pure soda-lime silicate glass (SLSG). A femtosecond Z-scan technique has been used for nonlinear characterization. In general one measures the transmission change as a function of intensity [2]. A Ti:Sa laser (wavelength $\lambda=800 \mathrm{~nm}$, pulse duration $\tau=100 \mathrm{fs}$, repetition rate $1 \mathrm{kHz}$ ) is used as excitation source. The excitation at $800 \mathrm{~nm}$ pump wavelength results in considerable two-photon absorption (2PA) for Ag NPs due to their surface plasmon resonance (at 410nm), whereas glass UV absorption requires at least three photons absorbed simultaneously. To investigate the nonlinear properties of these two-layer systems the Z-Scan measurements are performed by irradiating from particle as well as substrate side of the sample [3].
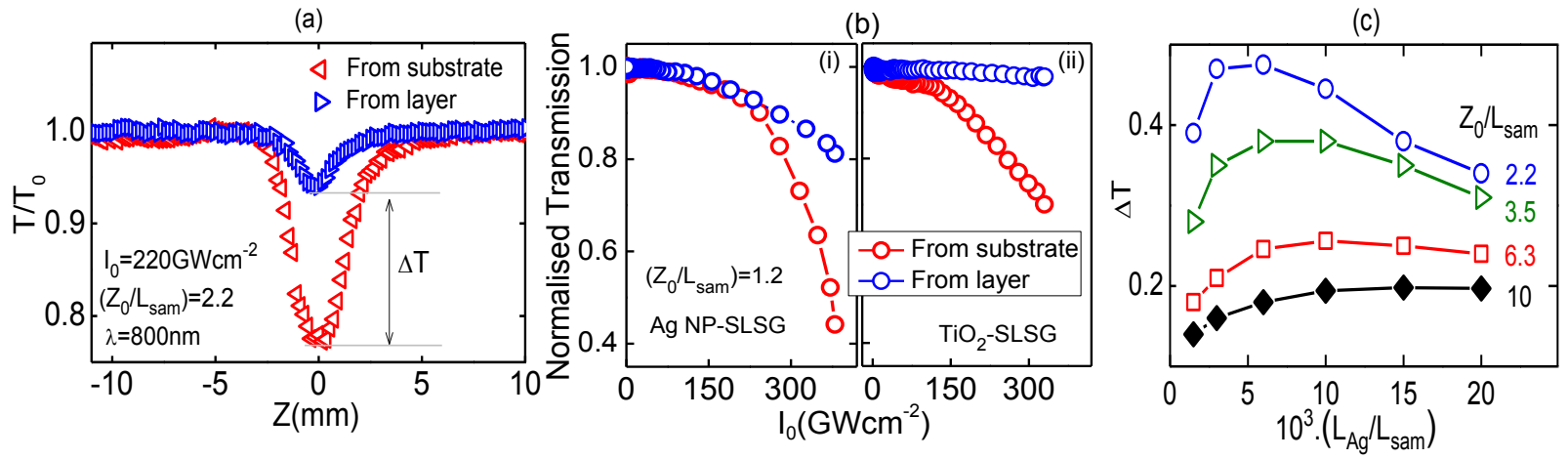

Fig.1. (a): OA Z-Scan curves measured in forward and backward directions; (b): Measured optical limiting behaviour of NP containing sample in forward and reverse direction of laser beam; (c): Results of numerical calculation representing the variation of anisotropy transmission $\Delta \mathrm{T}$ with relative particle thickness $\mathrm{L}_{\mathrm{Ag}} / \mathrm{L}_{\mathrm{sam}}$, calculated for different Rayleigh lengths.

Characteristic examples for results on Ag NP glasses are presented in Fig. 1a \& b. Experimental measurements showed an anisotropic transmission (optical diode like) behaviour when irradiating the sample in forward and backward direction, respectively. The observed anisotropy consists of an enhancement in nonlinear absorption upon irradiating from glass side of the sample (Fig. 1a: red open triangle) in comparison to the NP layer (open blue triangle). On the basis of a numerical model, this observation is explained by interplay between the selffocusing from glass substrate and $2 \mathrm{PA}$ at the Ag NP layer. The intensity dependent contraction of the beam radius, due to self-focusing upon irradiation from the glass side of the sample leads to higher peak intensity and thus to higher $2 \mathrm{PA}$ - in the particle layer than the direct entrance into the layer. The experimental and numerical studies (Fig. $1 \mathrm{~b} \& \mathrm{c}$ ) showed an increase in anisotropy, when the sample thickness $\left(\mathrm{L}_{\text {sam }}\right)$ approaches the Rayleigh length $\left(\mathrm{Z}_{0}\right)$ of the laser beam. A similar directional selectivity in nonlinear absorption is also observed in other two-layer systems comprising of titanium oxide $\left(\mathrm{TiO}_{2}\right)$ thin films coated on SLSG substrates (Fig. 1b (ii)). In this context the developed numerical model could disentangle the contribution from individual material layers which can be implemented for the Z-scan analysis of multi-layer based material structures.

\section{References}

[1] D.D Smith, G. Fischer, R. W. Boyd and D. A Gregory, "'Cancellation of photoinduced absorption in metal nanoparticle composites through counterintuitive consequence of local field effects", J. Opt. Soc. Am. B, 14, 1265(1997).

[2] M. Sheik-Bahae, A. A Said, T-H Wei, D. J Hagen, E. W Vanstryland, 'Sensitive measurement of optical nonlinearities using single beam", IEEE J. QE 16,113(1990).

[3] S. Mohan, H. Graener and G. Seifert, 'Diretional selective optical limiting of femtosecond pulses in simple transparent two-layer systems', Opt. Lett. 17, 4116(2012). 